\title{
ROLE OF WEB INFRASTRUCTURE IN INFLUENCING SECURITY CONCERNS AND PURCHASE INTENTION OF ONLINE CUSTOMERS
}

\section{RASHMI S CHAUDHRY \& PROF ANIL CHANDHOK}

PhD Scholar, Chandigarh University, Mohali, India

USB-Chandigarh University, Mohali, India

\begin{abstract}
The paper is a conceptual study exploring the effect of various dimensions of website infrastructure on customer risks and purchase intention in online buying environment. The dimensions related to website infrastructure or website quality identified in previous studies are extensively reviewed to develop a comprehensive model of causal relationship between the website quality, customer concerns and purchase intention. Perceived trust, privacy, product issues and transaction related concerns are the security concerns considered for the study.

E-commerce has been widely accepted across the world as the main buying platform. India alone has witnessed an increase in number of online customers from. Competition in online selling space is increasing rapidly, forcing sellers to adopt strategies that provide them a competitive edge and secure loyal permanent customers. Low cost of switching to other website is a main challenge. sellers are consistently formulating assurance strategies to mitigate fears and risks of customers to enforce trust and encourage positive purchase intention. Website infrastructure is an important element that connects sellers and buyers in e-commerce. It communicates the crucial information regarding the polices, practices, products or services displayed on website. The quality of website plays an important role in reducing customer concerns in online buying environment.
\end{abstract}

KEYWORDS: Web Infrastructure, Customers, Security Concerns

Received: Jun 08, 2020; Accepted: Jun 28, 2020; Published: Sep 15, 2020; Paper Id.: IJMPERDJUN20201245

\section{INTRODUCTION}

Rapidly changing technological interface within online selling space and consumers, have resulted in shifting of shopping experiences either partially or completely to the digital mode.

India has emerged as the fastest growing market for digital buying. Growth in revenue in this sector is expected to increase from US\$ 39 Billion in 2017 to US\$ 120 billion in 2020, witnessing an annual growth rate of $51 \%$, highest in the world. Internet user base in Indian online market is predicted to increase to 829 million from 560.01 million in September 2018. (ibef.org). Online retail sector has registered growth of 31\% in the year 201718,led by Flipkart, Amazon and Paytm Mall. Consumer Electronics emerged as the biggest contributor to e -retail sale with $48 \%$ share in the market, closely followed by Apparel at 29\%. (/www.ibef.org/ industry/ecommerce.aspx). Online shopping in FMCG sector has witnessed annual growth of 57\% in preceding seven years and is predicted to further grow by $18.6 \%$ by 2022.(Economic impact of internet services in India, internet and mobile association of India. IAMAI)Increased options for products/services, delivery at door step, flexible payment options, affordability, convenience are some of the reasons attracting consumers to online market spaces.( Greenstein, Marilyn and Todd M. Feinman, Electronic Commerce: Security, Risk Management and 
Control. USA: McGraw-Hill Companies, Inc; 2000).

India's online buying is not in accordance with its internet expansion. In addition to the legal interventions, online sites have also devised mechanisms and procedures to check or reduce the concerns faced by customers. To manage these customer risks, several information assurance mechanisms (e.g., policy statements and third-party web seals) have acquired importance for customer security.

It is observed by various studies that abandonment rates of shopping cart have increased mainly because of lack of trust in information related to either products/service, transaction or payment gateways or personal details.17\% of the dropout customers state concern for the payment as the main reason. Hence effective information systems are needed to convince current and prospective consumers about these concerns. McAfee secure, web trust, Trust-E, Semantic are some examples of trust seals used by online vendors such as Amazon, Flipkart,e- bay etc.

World wide web has become the new virtual address for e- buyers. Online buying platforms make use of websites to provide satisfactory services to accomplish diverse and dynamic customer needs. Retaining customers is a challenge for e-sellers due to low cost of switching to other websites( Hibah, Khalil,2017).Previous studies directly related good quality websites to higher retention rate as it alleviate customer concerns such as privacy, information security, transaction security and product or service related concerns. The perceived risks in online buying space make customers avoid online shopping leading to challenges such as shopping cart abandonment and unchecked websites. E-commerce websites are used by customers to procure purchase, product or transaction related information to reduce perceived risks and information asymmetry.

E- sellers in an attempt to make website attractive, include complex features that only add to customer confusion and apprehensions for using shopping website. Customers perceive website as an intermediary that provides answers to customer doubts regarding products, purchase platform, transaction procedure.

In emerging economies like India smartphone users are increasing at a high rate. They belong to rural areas and tier 2 and tier 3 towns that does not have high literacy rate. They are unable to decipher the complex website links and features. Hence websites should be modified to meet customer understanding capabilities. Only then they can be encouraged to use the e-commerce platforms.

The main objectives of the paper are thus to review the existing literature to identify the gaps in addressing the needs of customers and develop a comprehensive conceptual framework to determine the effect of website quality on perceived concerns of online customers.

\section{REVIEW OF LITERATURE}

This section is divided into two parts first part reviews the findings of previous studies on research variables including the meaning and context of website infrastructure or quality, customer security concerns and purchase intention. Second part reviews the dimensions and constructs identified in prior studies to facilitate the development of a new model. Finally, the literature review section is concluded with identifying main gaps in the existing literature.

\section{Website Infrastructure}

A website is the only medium of interaction between online buyers and sellers(Chen \& Dhillon 2003).There is wide literature available on impact of website quality on purchase intention. Various aspects of website quality from customers' 
perspective have been mentioned in preceding researches. The main attributes of website quality that have been explored are content quality, layout and technical adequacy( HsinChang and Su Wen Chen 2008).

Technical adequacy refers to level of ease with which customers can use the technological features. These features include navigation through webpage, web page loading, speed of opening content link etc.

Content quality includes features such as perceived usefulness of the website features, privacy, accuracy etc.

Layout denotes the overall design of the website such as colors,fonts and other multimedia attributes $\underline{\mathrm{H} \sin H \sin }$ Chang and Su Wen Chen 2008).

Website quality constitute the store atmosphere for online buying(Ethier et al,2006)

A well structured web site increase the chances of positive impression of the website on online customers.(Albert et al 2007).McKnight et al (2014) concluded the positive relation between the website quality and purchase intention. If the technical feature (deign attributes, page loading etc) of the shopping website are liked by the customers, they will develop a willingness to purchase. Customers like a simple design of the website that is easy and convenient to use because it reduces the feeling of uncertainty in potential customers. Technological complexities of using certain websites increase perceived risk of wasting time and lead to customer frustration.

\section{Customer Security Concerns}

Online buying can realize its full potential only after the security concerns are addressed. (Larose and Rifon,2007).Three main security concerns are addressed through this study, Privacy issue, product quality risks, and transaction related issues. Research insights related to these various issues in online buying are considered.

\section{Privacy Issue}

Privacy issue is a major concern for online customers today.(Smith et al,2011,Xu et al,2012)Unwarranted collection and use of the customer information pose a threat to customer information privacy.(Li 2012).This a major reason for negative word of mouth, shopping cart delaying and abandonment(Som \& Kim,2008). Customers feel insecurity while sharing their personal information such as payments details, their personal credentials etc.( Gaurav Bansal1, Fatemeh et al,2015).Privacy issue can be defined a the individual's claim to decide as to how, when and extent of communicating his/her personal information with others.(Malhotra et al 2004).In the context of online buying, customers' privacy issue refers to the fear of misuse of information by online seller (Som \& Kim,2008).Privacy is an important concern for online buying as it has a significant impact on customer trust. High level of trust further result in positive purchase intention. Prior studies such as by Smith et al 2007 have identified four dimensions of privacy issue: Unauthorized access, secondary use, collection and errors, these elements should be considered by customers while engaging in online buying process(Gaurav Bansal1, Fatemeh et al,2015).

\section{Product Quality Risks}

Product concerns arise out of the uncertainty when the seller is unable to communicate the genuine description of the product and hence customers are doubtful about the quality of the products or services delivered to them, adhering to the committed delivery standard and schedule.

Product type is an important determinant in online shopping. Experience, search and credence are three types of 
products classified by Nelson in 1970.Search products are the one for which complete information can be accessed before actually buying the product. e.g Books. Experience products can be defined as those for which information on product related attributes is known only after actually purchasing them, example apparels and clothing. Information on credence products can be ascertained only after using these products, example water purifier or a food delivered by a restaurant.(Rose Sebastianelli, Nabil Tamimi, 2018).Prior studies have considered product type as an important external factor that influence customer purchase intention to buy online. Karjalhoto, 2007 Mayso et al 2005 concluded in many researches that online buying intentions are stronger and more positive for search products as compared to the experience products.Product and service related information should be up to date, true and easy for customers to understand. Clarity and genuineness of this information are the main determinants of positive purchase intention in online buying.(: $\mathrm{L}$. Abdullah, R. Ramli, H. O. Bakodah et al., 2019) Online buying is challenged by many problems and information asymmetry is one of them. Incomplete and at times inaccurate information is the main reason for which customers hesitate to engage in online buying. Product quality should be appropriately described by online shopping sites.

\section{Transaction Information Risks}

Risks associated with payment and transaction at the time of purchase is referred to as transaction information risks. Security of disclosing personal and financial information such as credit or debit card details,login information, passwords, bank accounts is part of transaction security issues.(Mohammadreza Mousavizadeh et al,2017),)Online sellers make online transactions and payments secure with the use of assurance mechanisms such as Third party seals, policy statements. Many online sellers such as Swiggy, Zomato use Paypal, VeriSign to secure the sensitive personal information. Flipkart uses Flipkart assured as it own assurance to enthuse customer confidence. Amazon has its own security symbol assuring customers of safe transactions.

\section{Review of Dimensions and Measures of Website Quality}

Various dimensions and measures of website quality have been identified in previous studies. Website quality is interpreted differently by different researchers based on the importance of website quality in rendering a satisfactory experience and mitigating customers' perceived risks. Following section includes the variables of website quality identified in previous researches.

Ha Nam Khan Giao et al.(2020): Importance of website is gated as an information and interface system link between e- sellers and e- buyers. vBased on the buyers perspective measurement instrument used for the study included four variables: 1. website design related to interaction features such as navigation, information features and ordering procedure 2.Service capability that timely answers and solves customers' queries and purchase related problem issues. Reliability in serving customers needs with appropriate products and related information.4. Privacy and security features to enable secure transactions adhering toprivacy norms.vWeb site quality is positively related to trust, loyalty and satisfaction in online buying in this study, the findings were based on the empirical study of online buyers in Vietnam.

Salina Rasli et al (2018): Studied the impact of website quality on e-customer satisfaction. This study identified three dimensions of website quality website design, information quality and transaction services. Poor business website reflects on declining sales, high recurring costs, on the other hand a good quality website enables high customer trust. 
WEBSITE DESIGN: Refers to the appeal of website connecting sellers to prospective buyers. Appearance, information design layout and navigation are the main elements of the website quality. The hardware and software components of the website should be relevant to products or services displayed and made attractive to get enough traffic. It should be adaptive to customer needs and user friendly.

INFORMATION QUALITY: Physical contact with the product is lacking in the online environment rendering importance of product or service related information communicated through website-commerce platforms offers generous choice of product selection at best price with convenient and easy access. Information quality is evaluated on the basis of correctness, timely and relevant information. A good website facilitates informed comparison between products and make rational decisions.

SECURITY AND PRIVACY: Incorporation of security features on webpages entrust a feeling of protection against cyber and digital threats or risks.

TRANSACTION AND PAYMENT RELATED FEATURES: Payment gateway links should be clearly communicated to buyers. The research related all these elements of website quality to customer satisfaction.

Hibah Khalil (2017) : System, information quality and service are the three measures of website quality identified in the study that was conducted in China. These three factors are used to analyse the expectations of website users.

SYSTEM QUALITY: It is defined as the extent to which users perceive the website interface to be easily accessible, flexible and reliable. System limitation in the form of unresponsiveness, irrelevant and difficult to use navigation features dissuade customers from using the shopping website

SERVICE QUALITY: Include the extent to which users perceive the quality of website in terms of assessment and perception of service provided by e-sellers to fulfil customer expectations. The perceived quality of service features such as interaction and transaction services should be modified according to customer requirements.

INFORMATION QUALITY: Information conveyed through website should be correct, appropriate, and customized to meet individual needs of customers.

Sanjeev Prashar et al.(2017) Website Atmospherics have been related to customer behaviour. website quality is defined as web environmental cues that facilitate website satisfaction, they have been referred to as external factors affecting customers attitudes influencing online customer behaviour. S-O-R theoretical model has been used to study the impact of website cues on purchase intention. Website cues are the stimulus purchasing behaviour is the response and customer perception is the organism. This theory is used to identify motivating factors for online shopping and customer satisfaction. website cues or quality features identified in the study are :Information, effectiveness and entertainment. In this study association of local culture with website cues is also emphasised as the key parameter to influence the customer response towards shopping web portals. Principles, values and beliefs of online shoppers influence their attitude towards the website design. websites related to cultural elements win positive response of customer for navigation ease, appeal, and basic web portal features. Conclusions of the research are based on empirical study conducted on Indian online customers. In the Indian E-Commerce environment the external website cues have a significant impact on customer behaviour. favorable we site lead to enhanced customer involvement with the website leading to increased website satisfaction and positive purchase intention. 
Tiago Oliveira et al. (2017): The study related 'website infrastructure' to customer trust and purchase intention. Website layout should be easy and attractive to be liked by the users. It should be free of errors and efficient in functioning. The three main website features mentioned in the study are information quality, easy to use, and user friendly. If website is liked by the users it is preferred over website of competitors. Customer is dependent on the information provided by the website to fill up the gaps related to product information, transaction and payment gateways. Features of website navigation if fail to provide information privacy protection can make customers switch to other shopping portals. The importance for quality web features are more important for first time users.

Hsu et al. (2012) identified five factors related to website quality these are system quality, perceived playfulness, service quality, perceived information flow. Stimulus-Objective- Response (S-O-R) theoretical framework has been applied to establish relationship among research constructs. Influence of website quality factors was studied on customer perception of customer satisfaction with respect to hotel industry. High perceived service quality of website moderated the relationship between trust and purchase intention of onlinecustomers.

Prior studies on website cues have categorised it into two groups first one is related to interface features that includes display elements such as colour, font, text size and colour. These features have an emotional appeal and can be easily manipulated to match customer preferences. The other group of website quality is related to information quality. The quality of content communicated through website influence the customer's response towards exploring it and making a purchase intent. Some other studies Eroglu et al.2003 have classified website cues into high task

?(facilitating the accomplishment of buying objectives) and low task (Having marginal impact) features. Alshibly and Chiong (2015) laid stress on the importance on website quality for growth and sustainability of online business. There is no consensus among researchers on influence of website quality on mitigating customer concerns and affecting purchase intention, while most studies consider website as an important factor for reducing perceived risks and influencing purchase intention, there are some who find the role of website to be negligible as compared to other elements of e -commerce such as online reviews, policy statements, reputation etc.

\section{RESEARCH GAPS}

- Disconnect between information security needs of customers and their perceptiontowards web security.

- $\quad$ Lack of consumer knowledge about website quality and inability of e-sellers to address this issue.

- Prior studies have focussed on fragmented issues related to online information security, lacking a holistic framework to know in detail about the information security issues of online buyers and how efficient can website infrastructure be in mitigating these concerns and eventually influencing online buying behaviour.

\section{CONCEPTUAL MODEL FOR RESEARCH}

Research constructs for the study are partially based on the previous theoretical frameworks and research contributions and partially on the new insights gathered from observation of online buying behaviour practice. This part establishes the framework to relate website infrastructure with information security issues and purchase intention.

Research constructs have been explained in detail based on the existing deliberations of previous studies evaluated in literature review section. While, website infrastructure is directly related to customer security concerns, it indirectly influence purchase intention. This is clarified through further explanation of research construct items. 


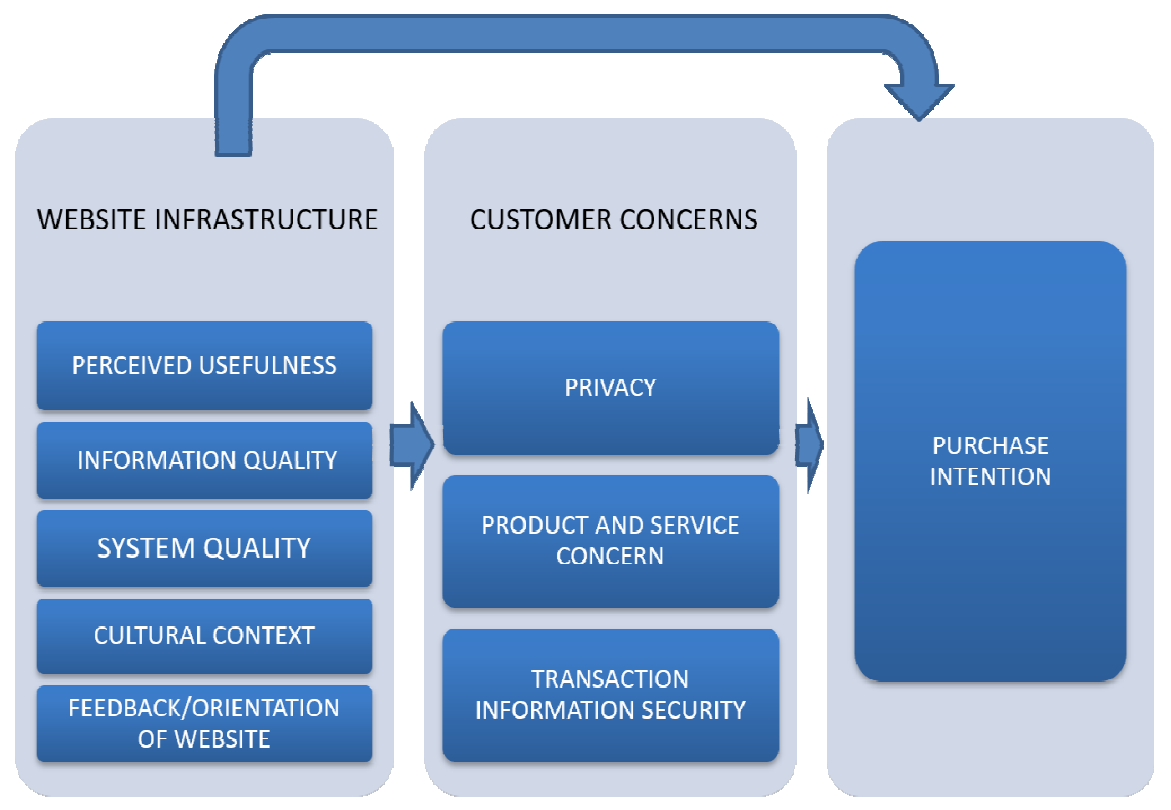

Figure 1: Conceptual Model

\section{RESEARCH MODEL CONSTRUCTS}

Present study attempts to establish the relationship of website infrastructure with information security concerns and purchase intention of customers in online buying environment. The main customer concerns considered are product quality risks, privacy and transaction information risks. Previous studies have indicated varying influence of website quality on perceived customer risks and purchase intention. Dimensions of research constructs have been identified to establish the relationship between selected research variables

Website Infrastructure: Website is the most important connect between e-sellers and e- buyers. Quality of a website determine how customers perceive this essential user interface and influence purchase intention. (Hibah Khalil (2017).Aesthetics, emotional appeal, usefulness, ease -of-use, information quality are some contstructs identified in previous studies. ( Hibah Khalil (2017). Hsu, Chang and Chen,2012 focused on service quality, information quality and system quality as the main features of website quality affecting customer behaviour. Website quality features determine the satisfaction level of online customers. features such as accuracy, convenience, responsiveness, content quality, technical adequacy(Chang and Chen,2008) have been identified in the previous studies that relate website quality to purchase intention and information security concerns.

- PERCEIVED USEFULNESS: Perception of online customers regarding the use of website features such as navigation,aesthetics should be useful to information needs of customers. This information is used for reducing perceived risks associated with online buying.(Yi Liu et al. 2017).

- INFORMATION QUALITY: Information quality has been considered as an important factor for increasing customer trust and mitigating customer concerns. Information cues such as price, product description affects customer perception of online vendor trust (Chenn \&Dibb, 2010). information quality refers to information being useful and relevant to the needs and expectations of customers.(Han Lee \& Park 2007).Information communicated through website should be relevant, updated and responsive.( Hibah Khalil (2017); 
- $\quad$ SYSTEM QUALITY: Ease of navigation,interface, appearance, layout and design are dimensions of system quality used by customers to evaluate websites and extract product and transaction related information. Relatively large amount of user information is collected through e-retail websites as compared to physical retail. (Gaurav Bansal et al;2015).Design, aesthetics, interface are the main elements of system quality.(Hibah Khalil (2017).

- CULTURAL CONTEXT: website should include features reflecting the local culture of users. The websites reflecting the users' values system and beliefs have more chances of being liked by the users. (Prashar, Sanjeev et al. (2017).Website design should include some cultural cues to establish an emotional attachment with potential customers.

- ORIENTATION AND FEEDBACK: Lack of knowledge and awareness regarding the website design is the main reason for avoidance of website. Hence, an orientation video link and an active interface should be provided to answer user doubts and concerns

Customer Trust: Customer trust is related to intention of disclosing personal information in online shopping. Esellers apply various methods to enforce customer trust in online shopping. Policy statements, third party seals are vendor generated mechanisms that mitigate perceived risks and result in increased trust. Online reviews a are based on customer generated information to build customer trust in online buying (K. Stouthuysen et al; 2017).Online shopping is limited by asymmetrical information about unfamiliar seller, virtually seen products, thus customers rely on available sources regarding buying environment to reach a decision making stage. Prior studies have identified various dimensions of customer trust. Institutional trust and competence trust are two important dimentions .Institutional trust is relate to structural attributes and is affected by product or warranty or return policies and guarantees. Competence trust on other hand is related to perception about e-seller's technical competence, skill sets etc. (K. Stouthuysen et al., 2017). Competence trust is affected more by online reviews.

Privacy Issue: is related to collection, usage, access, improper use and secondary access to personal information of customers. (Emma Lindark, 2015).Unauthorized or misuse of user information is referred to privacy related risks. When esellers fail to protect user information and misuse it by sharing with third parties without user consent it leads to privacy issues among customers. ( Mohammadreza Mousavizadeh et al,(2017),) identified experience, and awareness of privacy, demographic differences as defining aspects of privacy related issues.

Product Quality Risks: These are perceived risks of consumers related to quality of products and services being sold by a particular e-seller. These issues are related to receiving different products than what are expected by consumers, Returning of defective, faulty or unexpected products or delivery related problems. Information related to products and services are most important for customers to make purchase decisions in online buying environment. (Mohammadreza Mousavizadeh et al,2017).

Transaction Information Risks: Risks associated with payment and transaction at the time of purchase is referred to as transaction information risks. Security of disclosing personal and financial information such as credit or debit card details, login information, passwords, bank accounts is part of transaction security issues.(Mohammadreza Mousavizadeh et al,2017),)Online sellers make online transactions and payments secure with the use of assurance mechanisms such as Third party seals, policy statements. Many online sellers such as Swiggy, Zomato use Paypal, VeriSign to secure the sensitive personal information. Flipkart uses Flipkart assured as it own assurance to enthuse customer confidence. Amazon has its own security symbol assuring customers of safe transactions. 
Purchase Intention: Willingness to buy from a particular seller is referred as purchase intention. Assurance mechanisms have indirect effect on purchase intention. They influence purchase intention by mitigating perceived risks such as privacy, product and service related risks and transaction related information issues.

While Website infrastructure directly influence the customer concerns but it is indirectly related to purchase intention. The information provided through website reduces the customer concerns and reduced customer concerns lead to positive purchase intention, hence establishing the mediating role of purchase concerns in the proposed conceptual

These items used for measuring research constructs have been adapted partially from existing scales to increase construct validity. These have been highlighted in table:-

Table 1

\begin{tabular}{|c|c|c|c|}
\hline S. No & Research Variable & Construct Items & Source \\
\hline \multirow{9}{*}{1.} & \multirow{9}{*}{ Website Infrastructure } & Perceived usefulness & Yi bLiu, Xinlin Tang, (2018) \\
\hline & & Information quality & \\
\hline & & $\begin{array}{ll}\text { - } & \text { Relevant } \\
\text { Responsive updated }\end{array}$ & $\begin{array}{l}\text { Hibah Khaliln(2017); (Chenn } \\
\& \text { Dibb, } 2010\end{array}$ \\
\hline & & System quality & \\
\hline & & - Simple design & Hibah Khalil (2017), Gaurav \\
\hline & & - $\quad$ Aesthetics & Bansal et al;2015. \\
\hline & & - $\quad$ Technology level interface & \\
\hline & & Cultural context & Prashar, Sanjeev et al.((2017) \\
\hline & & Orientation and feedback & Self \\
\hline \multirow[t]{2}{*}{2.} & \multirow[t]{2}{*}{ Privacy Issue } & Misuse of personal information & $\begin{array}{l}\text { Mohammadreza Mousavizadeh } \\
\text { et al,2017). Kim and benbasat } \\
2006,2007\end{array}$ \\
\hline & & Secondary use of information & $\begin{array}{l}\text { MohammadrezaMousavizadeh } \\
\text { et al,2017). }\end{array}$ \\
\hline \multirow{3}{*}{3.} & \multirow{3}{*}{ Product And Service Risks } & Quality of products/service & $\begin{array}{l}\text { Mohammadreza } \\
\text { Mousavizadeh et al,2017). }\end{array}$ \\
\hline & & Return of faulty products & $\begin{array}{l}\text { Mohammadreza } \\
\text { Mousavizadeh et al,2017). }\end{array}$ \\
\hline & & Delivery related problems & $\begin{array}{l}\text { Mohammadreza } \\
\text { Mousavizadeh et al,2017). }\end{array}$ \\
\hline \multirow{2}{*}{4.} & \multirow{2}{*}{$\begin{array}{c}\text { Transaction Information } \\
\text { Risks }\end{array}$} & Disclosing financial information & $\begin{array}{l}\text { Mohammadreza } \\
\text { Mousavizadeh et al,2017). }\end{array}$ \\
\hline & & Payment & $\begin{array}{l}\text { Mohammadreza } \\
\text { Mousavizadeh et al,2017). }\end{array}$ \\
\hline \multirow{3}{*}{5.} & \multirow{3}{*}{ Purchase Intention } & Customer willingness to visit website & Wijoseno, Joko. (2017). \\
\hline & & $\begin{array}{l}\text { Customer willingness to make online } \\
\text { purchases }\end{array}$ & Wijoseno, Joko. (2017). \\
\hline & & $\begin{array}{l}\text { Customers have positive opinion of } \\
\text { buying online }\end{array}$ & Wijoseno, Joko. (2017). \\
\hline
\end{tabular}

\section{CONCLUSIONS}

Online buying environment is often limited by potential cyber threats which include compromised information system security and breach of customer privacy.( Workplace Privacy, Data Management \& Security Report, Jackson Lewis P.C., White Plains, NY, 2014 ) Identity theft, fraud, phishing, spoofing, delivery of wrong products, undefined contracts and agreements between buyers and sellers are some of the other important concerns faced by online buyers. Miyazaki and Fernandes (2001) proposed three major concerns of online buyers-privacy issue, third party fraud behaviour, issues related 
to system security. Increasing incidents of compromise of consumer data and privacy have rendered more vulnerability to information access. With increased adoption and use of e-commerce, consumers are concerned about the use of information they share with e-sellers. less knowledge about the software and the web design are the main reasons that make the customers or potential customers rely on sellers for protecting and securing their information. Hence it becomes all the more essential for these online sellers to strengthen the execution of information security mechanisms and need to increase the awareness regarding these mechanisms among customers to reduce information security concerns.

The present study will increase the understanding of role of website infrastructure on major customer concerns( ( Privacy, Product quality risks and transaction information risks) and purchase intention. It will bring out the importance of awareness of website design features in empowering online customers against all doubts and skepticism to engage in online shopping.

\section{REFERENCES}

1. Ebru onurlubaş, remzialtunişik (2019) "the mediating role of brand image on the effect of electronic word of mouth marketing on purchasing intention" the journal of academic social science

2. Rose Sebastianelli, Nabil Tamimi, (2018) "E-tailer website attributes and trust: understanding the role of online reviews", Online Information Review, Vol. 42 Issue: 4, pp.506-519, https://doi.org/10.1108/OIR-02-2016-0039.

3. Victor, Jose Joy Thoppan et al., (2018) "Factors Influencing Consumer Behavior and Prospective Purchase Decisions in a Dynamic Pricing Environment-An Exploratory Factor Analysis Approach"; Soc. Sci. 2018, 7, 153; doi:10.3390/socsci7090153.

4. Yi Liu, Xinlin Tang, (2018), "The effects of online trust-building mechanisms on trust and repurchase intentions": An empirical study on eBay", Information Technology \& People", https://doi.org/10.1108/.

5. Youwei Wang, Zhe Qu, and Bernard Tan (2018), “ How Do Assurance Mechanisms Interact in Online Marketplaces?” A Signaling Perspective Youwei Wang, Zhe Qu, and Bernard Tan; 0018- 9391; 2018 IEEE. Doi.org ;10.1109/TEM.2017.2786275.

6. Hibah Khalil (2017); The Role of the Quality of a Website in Consumer Perception,University og North Florida

7. Wijoseno, Joko. (2017). Perceived Factors Influencing Consumer Trust and Its Impact on Online Purchase Intention in Indonesia. 10.21275/8081706.

8. K. Stouthuysen, I. Teunis, E. Reusen, H. Slabbinck,(2017) "Initial trust and intentions to buy: The effect of vendor-specific guarantees, customer reviews and the role of online shopping experience," Electronic Commerce Research and Applications doi: https://doi.org/10.1016/j.elerap.2017.11.002

9. Mohammadreza Mousavizadeh, Dan J. Kim, Rui Chen,(2017), " Effects of Assurance Mechanisms and Consumer Concerns on Online Purchase Decisions: An Empirical Study, Decision Support Systems, doi:10.1016/j.dss.2016.09.011.

10. Nisar, T. M., \& Prabhakar, G. (2017). What factors determine e-satisfaction and consumer spending in e-commerce retailing? Journal of Retailing and Consumer Services, 39, 135-144.doi:10.1016/j.jretconser.2017.07.010.

11. Tiago Oliveira, Matilde Alhinho, Paulo Rita, Gurpreet Dhillon,(2017); “ Modelling and Testing Consumer Trust Dimensions in E-commerce," Computers in Human Behaviordoi: 10.1016/j.chb.2017.01.050 
12. Gaurav Bansal, Fatemeh 'Mariam' Zahedi, and David Gefen(2015), “The role of privacy assurance mechanisms in building trust and the moderating role of privacy issue"European Journal of Information Systems(24(6), 624-644. doi:10.1057/ejis.2014.41.

13. HsinHsin Chang and Su Wen Chen (2008) "The impact of online store environment cues on purchase intention", Online Information Review, Vol. 32 No. 6, pp. 818-841.

14. Gaurav Bansal, Fatemeh 'Mariam' Zahedi, and David Gefen,2008, "The moderating influence of privacy issue on efficacy of privacy assurance mechanisms for building trust : A multiple context investigation”, ICIS proceedings 2008.

15. Yamagishi, T., Yamagishi, M.(1994); “ Trust and commitment in the United States and Japan. Motivation and Emotion” 18, 129-166 (1994).

16. Fang, Y., Israr, Q., Heshan, S., Mccole, P., Ramsey, E. and Kai, H.L. (2014), "Trust, satisfaction, and online repurchase intention: the moderating role of perceived effectiveness of e-commerrce instituional mechanisms", MIS Quarterly, Vol. 38 No. 2, pp. 407-427.

17. Wang, Y.D. and Emurian, H.H. (2005), "An overview of online trust: concepts, elements, and implications”, Computers in Human Behavior, Vol. 21 No. 1, pp. 105-125.

18. Wells, J.D., Valacich, J.S. and Hess, T.J. (2011), "What signal are you sending? How website quality influences perceptions of product quality and purchase intentions", MIS Quarterly, Vol. 35 No. 2,pp. 373-396.

19. Yang, K., Li, X., Kim, H. and Kim, Y.H. (2015), "Social shopping website quality attributes increasing consumer participation, positive eWOM, and co-shopping: the reciprocating role of participation”, Journal of Retailing and Consumer Services, Vol. 24, May, pp. 1-9 
